Many persons write and speak by a process of soundconception. In that case the ideal present to the automatic faculty for reproduction in written or spoken words is auditory. This gives rise to a special class of errors, in which words or letters having a similar sound are substituted, and the defects of pronunciation proper to an individual, a dialect, or a language, will predispose to particular mistakes. For example, were or wocar will be written for where, witch for which, wen for when, if no difference in the sound is habitually recognised. The substitution of is for his or er for her is a cormmon misadventure with those who do not aspirate the $h$, or the opposite error may be made by persons who either in jest or habitually sound the $h$ when it is absent. Knew for new is a frequent blunder, and such substitutions as cousin for cozen, not for knot, rap for wrap, are obviously probable. It would be easy to multiply examples, but these will suffice. A curious circumstance in connexion with this writing or speaking from mental sound-and it is generally possible to detect the nature of the habit by the presence of either special class of errors in writing--is that the individual generally (unconsciously, it may be) composes in a peculiar rhythm, which is often adopted from some verse or song which impressed the mind in infancy. Occasionally the recognition of this rhythm or time will supply the key-note to character; and, perhaps, without being aware of the circumstance, it is by this suggestion experts in character-reading succeed in making very shrewd guesses as to the leading qualities and habits of a mind from handwriting. Persons who write or speak from an ideal of sound generally employ the same formula in the operations of memory. A man who uses mental sight in this way will gaze intently when he forgets anything, or perhaps close his eyes to avoid distraction, while a person who employs mental sound is more likely to put his finger to his lips, as though to enforce silence, and perhaps incline his head as though listening. I merely mention this in passing. It will be evident that the facts we have been reviewing supply the strongest possible evidence that it is by a process which $I$ have called mental-reflex errors of the general classes noticed hecome habitual. They begin in the sphere of mental operations by false conceptions and defects in thought-processes, and being reflected in on the brain, they give rise to new combinations, such as those which form the physical basis of memory. They are repeated, and the automatic apparatus develops a special nervous facility for their commission. They then become "habitual" or, which is the same thing, automatic, and beyond the control of the will, which can at best only keep a watchful eye on the way the lesser faculty performs its functions, and correct its mistakes.

Few, if any, of the considerations now submitted can claim attention on the score of novelty, but $I$ have ventured to throw them together in the hope of attracting the notice of practitioners-and especially of those engaged in the continuous supervision of families-with the important stages of mental development under their observation, and the opportunity of suggesting corrections and amendments at their command. Nothing is done, either in act or thought, without impressing the brain aud nervous centres with a certain facility for repeating the exercise. It is impossible, therefore, to exaggerate the importance of avoiding everything that is likely to lay the foundation of a bad habit, of mind or body. When a habit is once formed it can seldom be remedied directly by the will. The cure must be effected by destroying or superseding the vicious automatic combination which has been created reflexly. This can be most readily and effectually accomplished by some process of training which will create a new automatic combination incompatible with, and destructive of, that we desire to abrogate. It is, in fact, useless to try to antagonise the habit directly; it must be supplanted by another. The utmost that can be achieved by interference with drugs is to interrupt a morbid train of activities by throwing the nervecentres into a state of repose, restoring their tone when debilitated, or preventing the irregular and explosive discharge of energy. Listly, I venture to urge a more constant professional recognition that habit plays an important part in the formulation, if not also in the causation, of disease. Types of nerve, brain, and reneral disease are often developed by habit, and the mind is the prime mover in producing the conformity. The phenomenon is a mental reflex. It originates in the mind, reacts on the brain, and reappears in the rank of mental activities as a reflex. Even if mind be simply a form

of cerebral energy - which I see many grave scientific reasons to disbelieve,-there must be an outer zone, of functional intellectual energies, in and from which all ideo-motor forces act and react. Morbid manifestations of habit require to be treated on the principles $I$ have tried to indicate rather than to explain.

London.

\title{
ANTISEPTIC OSTEOTOMY FOR GENU VALGUM, GENU VARUM, AND OTHER OSSEOUS DEFORMITIES.
}

BY WILLIAM MACEWEN,

SURGEON AND LECTURER ON CCINICAL SURGERY, ROYAL INFIRMARY, GLASGOW.

As, in some instances, figures convey to the mind a much more distinct impression, and engender a more vivid idea, than can be produced by written description, it is thought expedient to present several varieties of osseous deformity which have been operated on by me, and, for comparison along with these, the results in several instances. It was considered that photography was the most exact method of securing the primary figure, and the photographs were placed in the hands of an accurate engraver (Mr. Stephem Miller, of Glasgow) for transference to wood. In one or two instances, where the deformity was very bad, the persons could not stand to have their photographs taken; and as sitting or lying was not suitable, the idea of figuring them was renounced. In these cases, as well as in the others, accurate measurements were taken from fixed points. The woodeuts and the accompanying description form an appendix to the paper on osteotomy published by me in THE LANCET of Dec. 28th, 1878.

Fig. 1 represents a case of knock-knee, which, though well marked, may be regarded as a medium instance; the deformity often being greater. In some cases the distance between the two internal malleoli, taken as the patients lay on their backs in bed, while their knees touched, measured eighteen inches, and in two cases twenty inches. The latter were unable to walk prior to the operation, whereas after the operation they were able to go freely about, one such person (the first operated on) walking a distance of fourteen miles in one day without fatigue. In one instance of knockknee of the right leg and bow-leg of the left, the internal malleolus of the right leg was eleven and three-quarter inches to the outside of a perpendicular drawn in a line with the body and at the level of the internal condyle. It will be seen that if this had been a case of double knock-knee, of equal severity in both limbs, the distance between the two internal malleoli would have been twenty-three inches and a half.

Frg. 1.

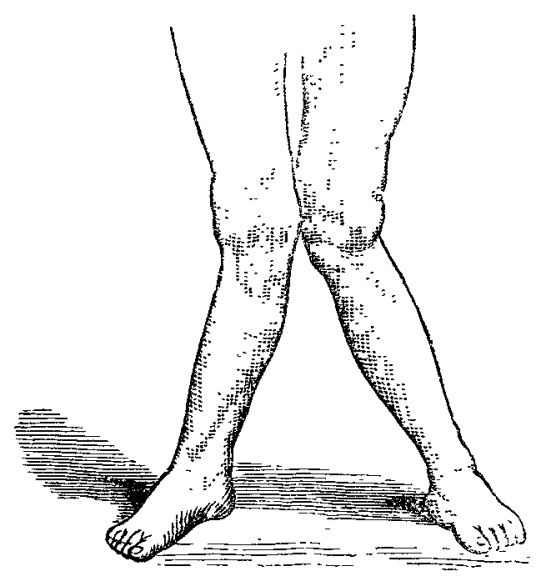

Fig. 2 shows a case of double knock-knee of more pronounced character. The figure represents the only position in which the person could stand easily. The left knee overlaps the other, the right knee being seen from behind and to the left side of the left. The measurement between the two 
malleoli, taken as above, was fifteen inches. In walking, the one limb had to circumnavigate the other to a very considerable extent.

Fig. 3 is a case of knock-knee of the right limb and bowleg of the left. This has happened in my experience more often in girls than in boys, but I am inclined to attribute it to fortuitous circumstances connected with the cases which have come before me hitherto, and do not believe that it will be found a general rule. In such cases two osteotomies are performed at the same time, both limbs being straightezed. The knock-knee is rectified by the femoral incision and the bow-leg by the division of the tibia at the spine and the simple fracture of the fibula. In some instances, in young persons, a green-stick fracture of the fibula ensues.

FIG. 3.

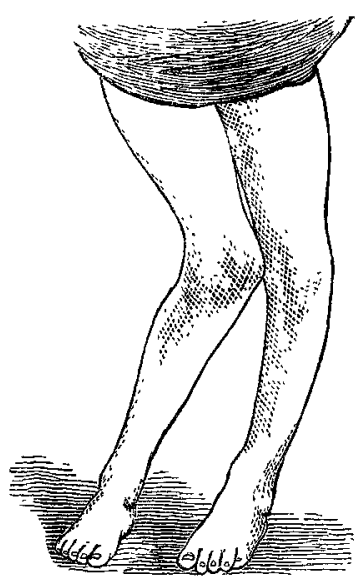

Frg. 4.

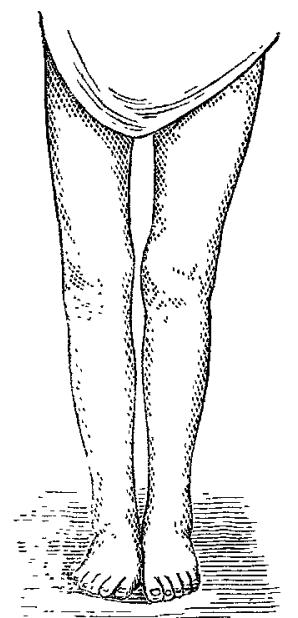

Fig. 4 is one of the resnlts of operation by the fernoral incision for knock-knee. It is an average result : some are better, others not quite so good, though all are straight. It would be useless repetition to represent here all those which have been photographed, as they represent merely a series of straight limbs. The movement of the knee-joints is very free. One lad showed to me his power of flexion by dropping on his knees and rising without assistance, as his occupation required; and another could, by a quick movement, touch the gluteal region with his heel.

Fig. 5 is the result of a case somewhat similar to that represented in Fig. 3, only in this instance the deformity in both limbs was more marked. The right limb was the one which was bowed outwards, and the left the knock-knee. When bow-leg and knock-knee occur in the same individual the angle of the in-knee is often greater than what is found when both limbs are knocked.
FIG. 5.

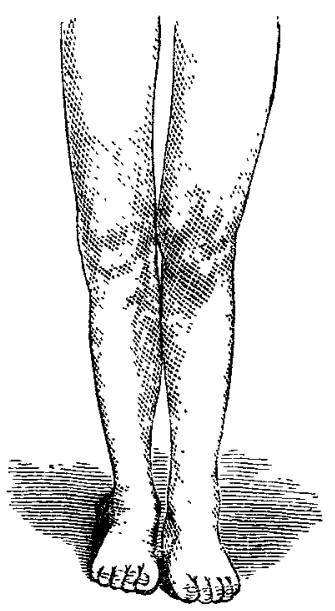

FIG. 6.

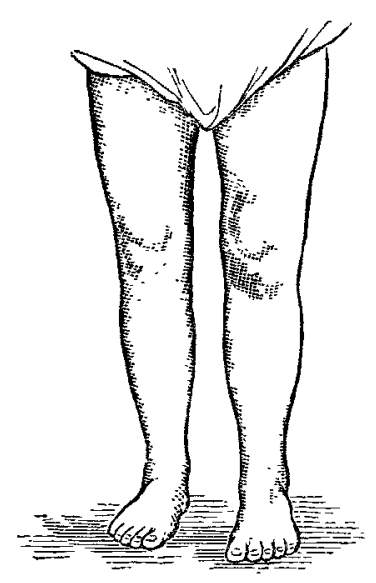

Fig. 6 shows the result of femoral incision in a case of single knock-knee, the left limb being the one which was affected. In such cases there is generally a slight affection of the neighbouring limb (most often bent outwards), but in this instance the right limb was well formed. This occasioned the deformity in the left limb to be all the more marked. There was a compensatory curve in the trunk, and she walked with a very considerable halt. When the knees were placed together as she lay in bed on her back, there was a distance of nine inches between the two malleoli.

Fig. 7 is a case of rickety deformity. $\alpha$ represents the front view of a right leg which was affected with a tibial curve, the convexity being forward. Several osteotomies were performed at the same time to rectify this, and $b$ is the front view of the same leg after the rectification of the curve.

Fig. 7.

FIG. 8.
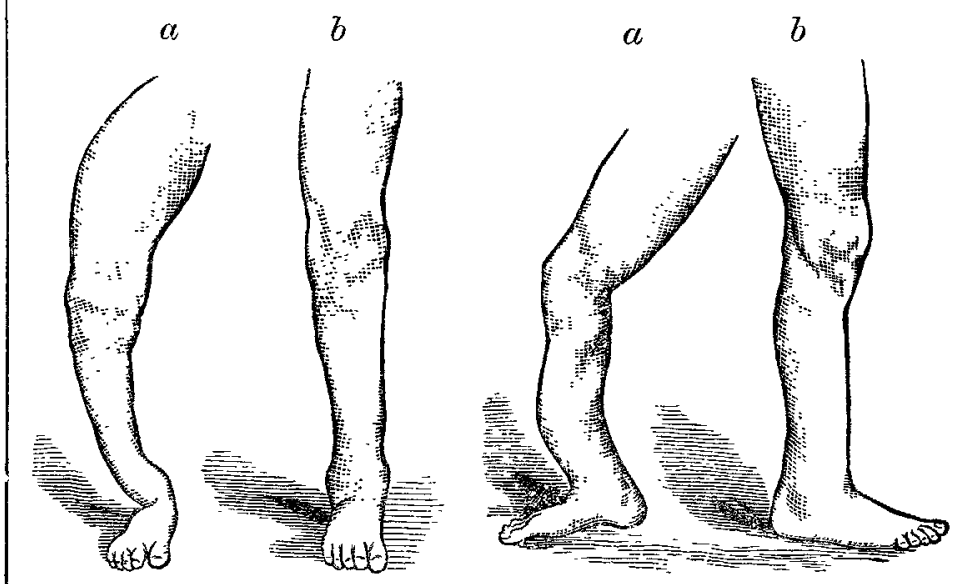

Fig. 8 is the side view of the same limb; $a$, prior to the operation; $b$, after the operation. The deformity was rectified by a series of simple incisions with graduated chisels, so as to leave $\mathbf{V}$-shaped openings, with the base looking anteriorly. In some other cases of the same kind I removed a surplusage $\mathbf{V}$-shaped portion of the bone from the most convex part, and the result was equally satis. factory. The wound in this latter case was much larger than in the simple incisions.

Fig. 9 is a diagrammatic figure drawn to scale, representing a case (sixteen years of age) of angular anchylosis of the left knee of several vears' standing. The tibia was thrown well to the posterior border of the femoral condyles, and these latter structures had the elliptoidal form which they are apt to assume when the pressure of the weight of the body has been long removed from their extremity. In this instance the elongation amounted to fully an inch greater than those of the corresponding limb. When the knees were placed together as the patient stood, the toes of the affected limb were two inches and the heel seven inches from the floor.
FrG. 9

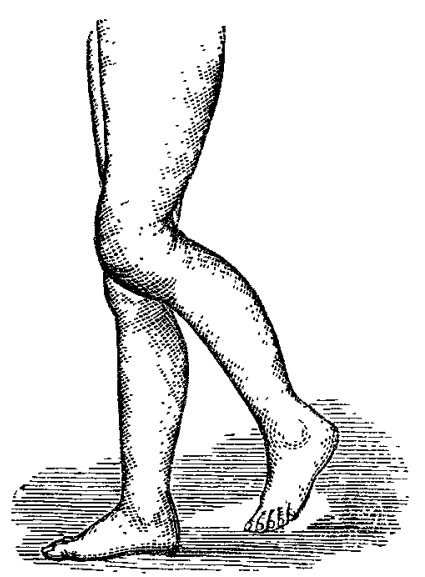

FIG. 10.

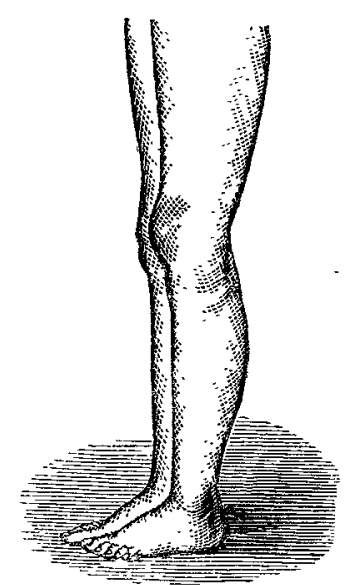

Fig. 10 is the result of the above case, the affected limb being brought into a line with the other. Shortening generally ocrurs in such cases, half an inch to an inch, and sometimes even a little more, but in this instance, and also in one operated on since, there has been no shortening. There is the prominent knee still quite apparent, but otherwise there is no deformity. The wound was over the inner side of the patellar ligament, and the cicatrix now measures a quarter of an inch. Though most of the cases of angular anchylosis of the knee are the sequel o of diseased conditions, yet the same kind of deformity may result from injury. In one case (patient twenty-six years of age), having a traumatic origin, the limb was straightened by me with a very satisfactory result.

Glasgow. 